\title{
Skin and Liquid Crystal: A Brief Review on their Similarities
}

\author{
HAMDAN SUHAIMI* and LAILI CHE ROSE \\ School of Fundamental Science, Universiti Malaysia Terengganu, \\ UMT 21030, K. Terengganu, Terengganu, Malaysia. \\ Corresponding author E-mail: hamdans@umt.edu.my \\ http://dx.doi.org/10.13005/ojc/320434
}

(Received: July 17, 2016; Accepted: August 19, 2016)

\begin{abstract}
Looking oneself directly into a mirror and what does one see? The answer is of course one's face. Taking good care of ones skin is synonymous to beauty and healthy life style. However, beauty last only as thick as a skin layer so the saying goes. While, liquid crystal, as the name implies, it looks like a crystal but flow like a liquid. Thus, how does this stucture called liquid crystal relate to skin and beauty? As most of us are aware skin and liquid crystal all around us, be it naturally or in technological applications. Our body body are covered with skin and liquid crystals. Surprise as it may seem but that is a fact, albeit peculiar to some. Classic example of natural liquid crystals are protein and cell membranes, while in industrial application such as electronic devices, for instance, screen of our laptop, digital watches and latest application in cosmeceuticals that is liquid crystal crystal emulsion. The question now arise is how does skin relate to liquid crystal? Why is it that this structure is crucial to the structure and function of skin? How does it relate to the delivery system of active ingredients which is important in many cosmeceuticals product? This paper will provide a brief review on the relationship of these two entities and present some work done in this area of interest. A model for the lipids of the top most layer of the skin namely stratum corneum will be highlighted.
\end{abstract}

Keywords: Skin,stratum corneum, liquid crystal, surfactant.

\section{INTRODUCTION}

\section{The structure of skin}

The skin (Figure 1a) together with its derivatives such as glands, nails, hair and other structures are termed as the Integumentary System. This integument is the skin covering the body which is in direct contect with the external environment and serves as a protective layer of the body. It is also known as the cutaneous membrane. Being a boundary between the internal body and outside system, it is subjected to wear and tear, cuts and bruises. It acts as a barrier to water in the body that might leak out or from hazardous materials that might penetrate into the body. It is also can be an indicator of the health and character of a person. 
Traditionally, skin or integument is divided into two major layers. The outer covering layer is called the epidermis. While the inner layer is called the dermis. The dermis is made up of the papillary layer at the top and the reticular layer at the bottom. Between these layers there exist plethora of structures interchilating and crossing with each other. Beneath the skin is the subcutaneous tissue or hypodermis layer. These three layers differ in thickness in different parts of the body. As a way of illustration, in order to appreciate the effect of the dimension of size skin, the size of skin can be visualised as thick as a piece of A4 paper. Depending on the type of skin, there are 4 or 5 layers within the epidermis as shown in Figure 1b. These sublayers are stratum basale, stratum spinosium, stratum granulosum, stratum lucidum (only in thick skin) and stratum cornem. The principle cell type in the epidermis is called keratinocyte and are largely found at the first three layers of the epidermis. These keratinocytes from the deepest layer of the epidermis namely the stratum basale, undergo cell division by mitosis and thus provide a continuous supply of new cells. As a result of the division these cells are being pushed upwards towards the surface and finally being shed away from the surface after a certain period.

\section{Stratum Corneum}

The shape of the dividing cell changes as they are being pushed upwards by the newer cell. It gradually becomes flattened at the subsequent layers which are then are filled with dead or the nondividing keratinocytes. Finally, as a consequece of this continuous division, a strata of about 20-30 layers of interlocking keratinized cell which are are 0.5 ìm in thickness and 30-40 ìm wide ${ }^{1}$. This layer
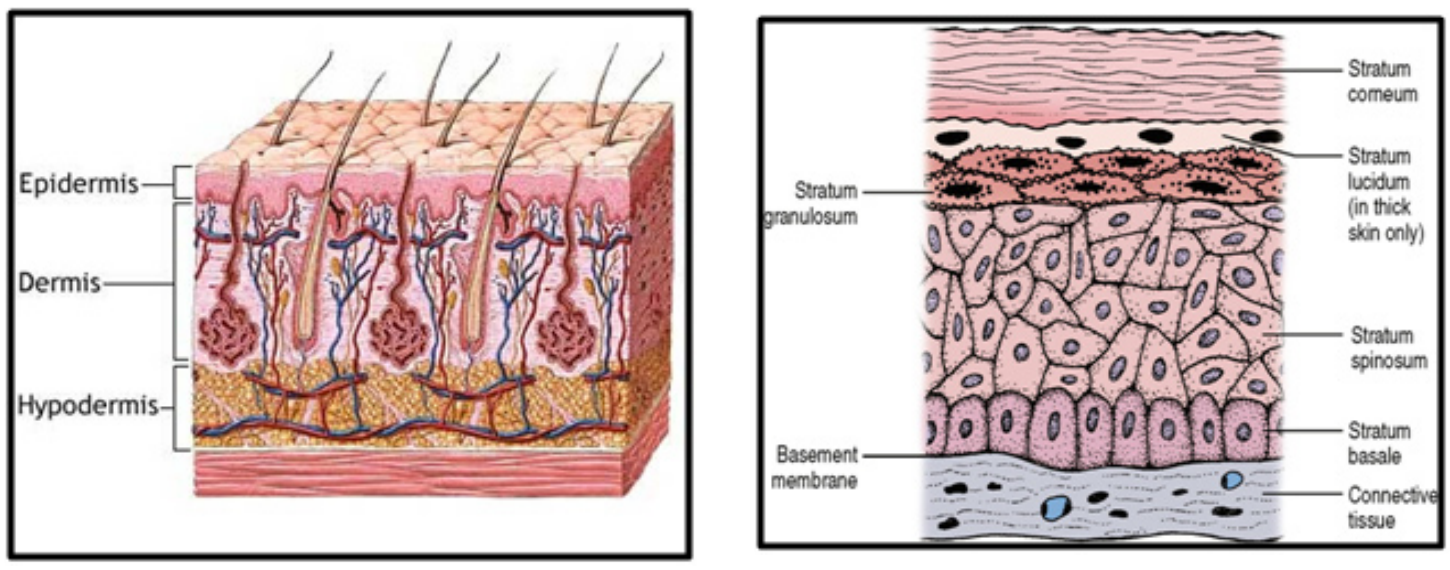

Fig. 1: The structure of skin (http://medicineworld.org/news/news-archives)

\section{CELL CYTOPLASMA}

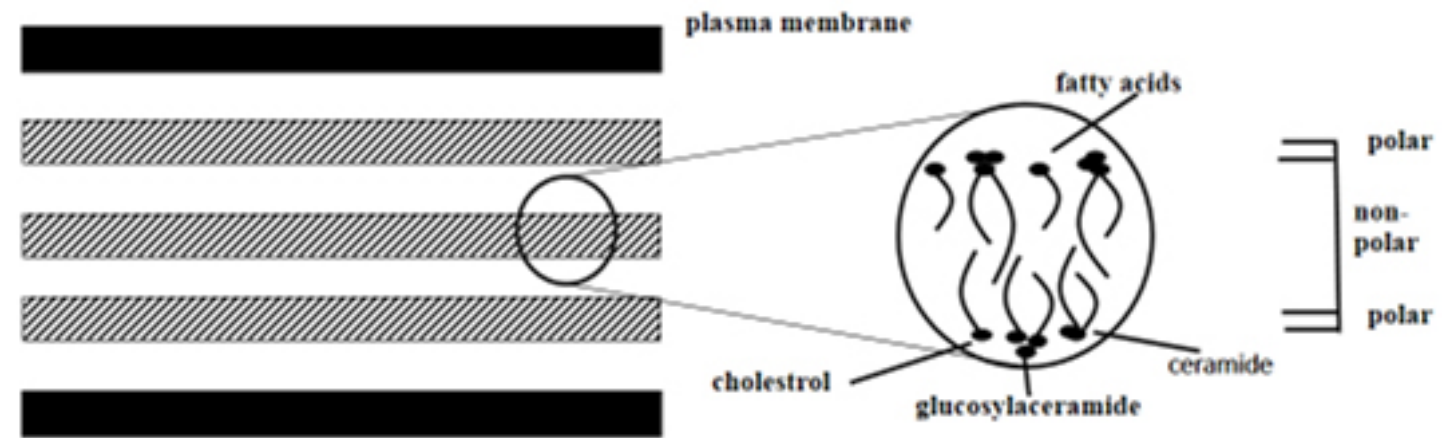

Fig. 2: Diagram showing the arrangement of lipids forming bilayers as postulated by Elias ${ }^{13}$ 
is called stratum corneum. In order to complete the process, desquamation must take place. At this stage, the cells are shed away from the skin. Normally, it takes a period of 45 to 75 days from the birth to final desquamation.

Studies has shown that the presence of stratum corneum reduces the water evaporation rate by a factor of $25-50^{2}$. It also prevents the uptake of water into animal body, stbilizes the body temperature and also serve as a barrier to chemical and biological attack from the environment. Vast attention has been directed to the water transport through the stratum corneum $^{3-6}$. Most evidences indicate that the lipids content of the stratum corneum to be the main factor in the stratum corneum barrier to trans dermal
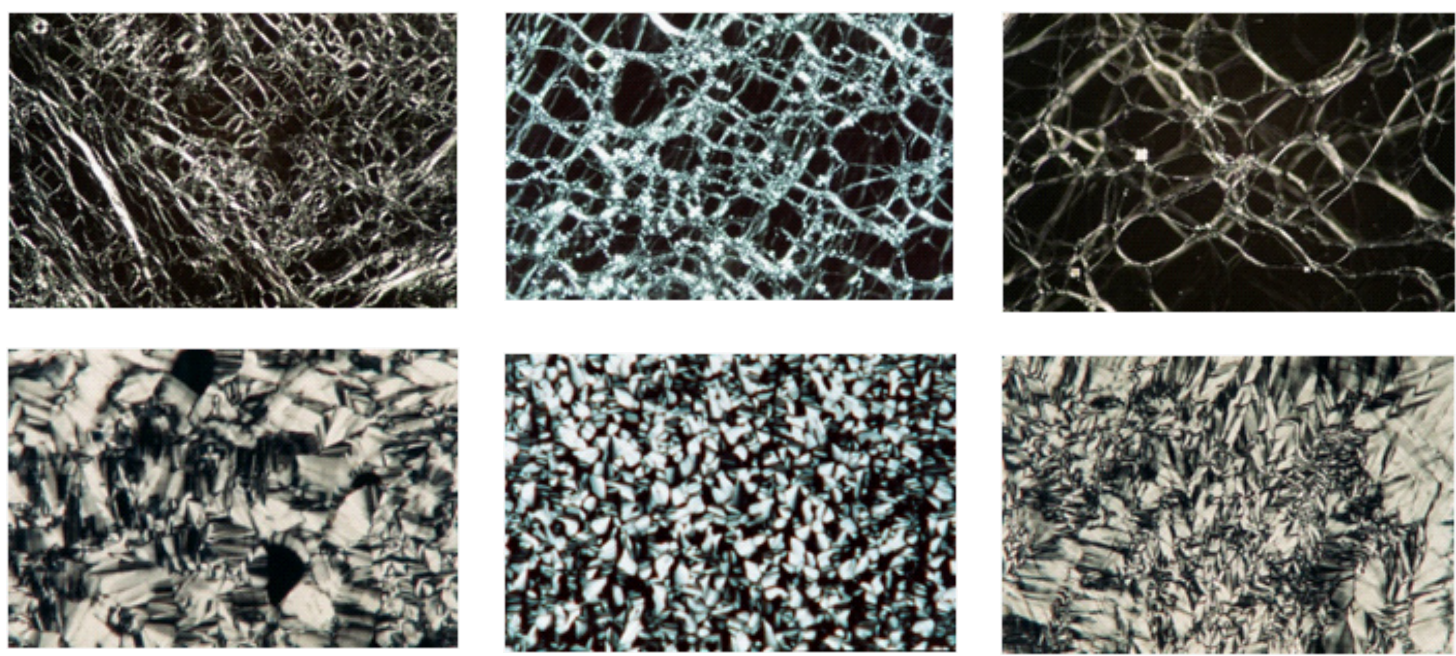

Fig. 3: Typical optical pattern of lyotropic liquid crystals

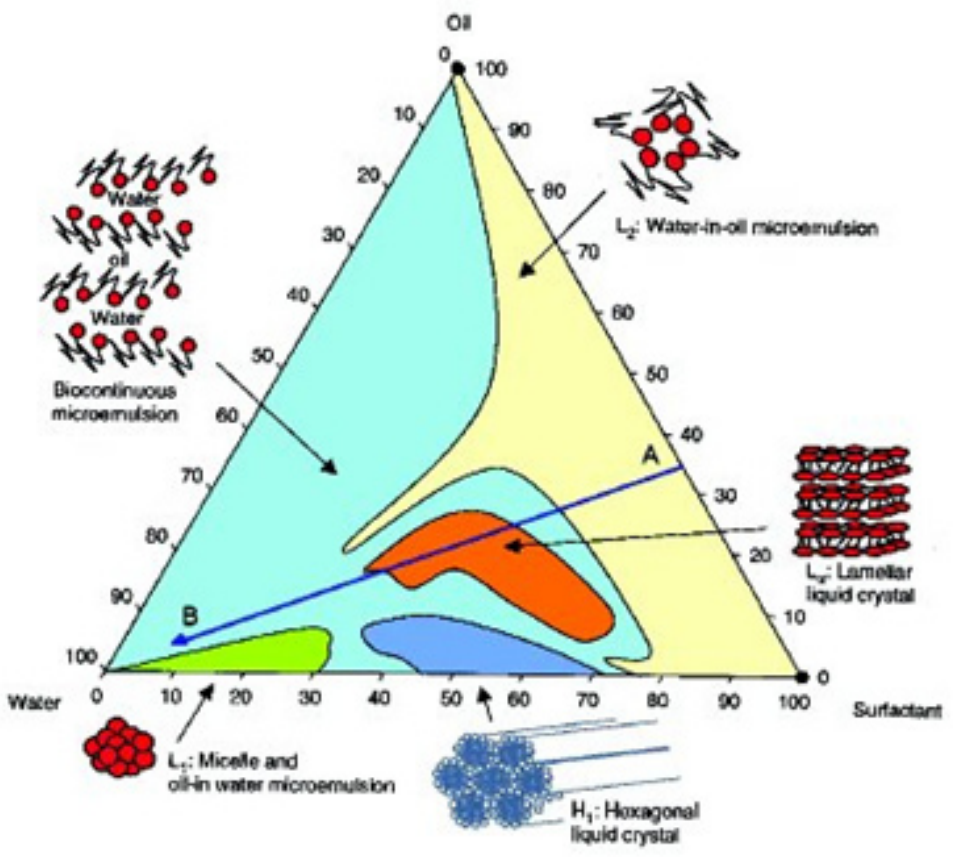

Fig. 4: Typical illustration of surfactant assciation behaviour 
water transport. Extensive investigations towards the individual structure of stratum corneum lipids ${ }^{7-9}$ as well as their molecular organization.

\section{Epidermal lipids}

The structure of the lipids mixture of the stratum corneum has been a subject of tremendous investigations. Most notable are those by Elias ${ }^{10-11}$, who has traced the origin and characterized the lipids of stratum corneum. Stratum corneum can be depicted as a two-compartment system analogous to brick and mortar, in which cells can be analogized as bricks, and intercelluar lamallae to mortar. A method was developed to isolate the stratum corneum lipids by using stansted cell disrupter and proteolytic digestion $^{12}$. Lipids of the stratum corneum was meticulously characterized and tabulated as in shown in Table $1^{10}$.

It shows that the total lipid content varies at different part of the body and it also displays abundant ceramides, free sterols and fatty acids. Based on the lipids found in the stratum corneum, Elias postulated that the lipids would form a bilayer. This was on the basis that ceramides and fatty acids having polar and nonpolar character. Figure 2 shows the arrangement of lipids as postulated by Elias ${ }^{13}$.

\section{Liquid Crystal}

Surfactant association structures have a rich literature and continually increasing. To date (Date of search October 30, 2015; Search keyword: 'liquid crystal'), a quick search online, show 2,850,000 articles were published involving liquid crystal (http:// apps.webofknowledge.com). It ranges from micellar concept by McBain to the structure of liquid crystals and the phase behaviour of surfactants systems ${ }^{14-16}$. They are many different types of liquid crystal but can be conveniently divided into two main types namely thermotropic and lyotropics. Thermotropics liquid crystals are obtained by changing the temperature, while lyotropic liuid crystal by addition of solvents to surfactant systems. In this paper, lyotropic liquid crystal will be highlighted because of its great importance in the stability of the pharmaceutical and cosmetic applications.

As the name implies, liquid crystals flow like a liquid and but the molecules are oriented in a crystal-like manner. It is characterized by its long-range order and short-range disorder ${ }^{17}$. When observed under polarized microscope, different liquid crystals will exhibit signature textures as shown in Figure 3.

Table 1: The characterization of human epidermal lipid ${ }^{10}$

\begin{tabular}{|c|c|c|c|c|c|}
\hline & $\begin{array}{l}\text { Outer Stratum } \\
\text { Corneum }\end{array}$ & Abdomen & Leg & Face & Plantar \\
\hline Lipid Wt (\%) Fraction & & 6.5 & 4.3 & 7.2 & 2 \\
\hline Polar Lipids & 2.3 & 4.9 & 5.2 & 3.3 & 4.5 \\
\hline Cholesterol sulfate & 3.4 & 1.5 & 6 & 2.7 & 3.4 \\
\hline Neutral Lipids & 68.4 & 77.7 & 65.7 & 66.4 & 63.9 \\
\hline Free Sterols & 18.4 & 14 & 20.1 & 17.3 & 23.1 \\
\hline Free fatty acids & 15.6 & 19.3 & 12.7 & 19.7 & 20 \\
\hline Triglycerides & 11.2 & 25.2 & 20.1 & 13.5 & 8.5 \\
\hline Nonpolar NLs & 19.4 & 16.3 & 11.7 & 15.9 & 12.3 \\
\hline Sterol/was esters & - & - & - & 6 & 6.4 \\
\hline Squalenes & - & - & - & 6.9 & 3.8 \\
\hline n-alkanes & - & - & - & 2.8 & 2.1 \\
\hline Spingolipids & 26.6 & 18.1 & 25.9 & 26.5 & 30.1 \\
\hline \multicolumn{6}{|l|}{ Glycolipids-1 } \\
\hline \multicolumn{6}{|l|}{ Glycolipid-2 } \\
\hline \multicolumn{6}{|l|}{ Ceramides } \\
\hline Ceramides/NLs & & & & & \\
\hline
\end{tabular}


Different types of lyotropic liquid crystal are formed from different combinations. Interlayer spacing ranging from 10 to $100 \AA$ are characteristic for the lyotropic liquid crystal employing low-angle $\mathrm{x}$-ray diffraction. The wide-angle $\mathrm{x}$-ray diffraction shows aspacing of $4.5 \AA^{18}$.

\section{Relationship between skin and liquid crystal}

As postulated by Elias the lipids to be present in the stratum corneum would form bilayer ${ }^{13}$. These findings have prompted many work such as Friberg ${ }^{19}$ to investigate further. A few model epidermal lipid were formulated based on the characterization of the human stratum corneum ${ }^{19-21}$. Initial attempts to form bilayer using the model lipid mixture resulted in a completely heterogenous matrix of liquid fats, undissolved solid, and water ${ }^{19}$. Friberg then pointed out that the model would form bilayer after taking into consideration of some important factors. The most important factor is the $\mathrm{pH}$ of the skin $^{22-23}$. The pH of a normal and healthy skin is in the range of $4.2-6.0$. In this acidic nature of the skin, the carboxylic acids do not exist as acids but are partially saponified. Hence, the skin conatins a mixture of soaps and the carboxylic acids. Such a mixtures has a surfactant association structure as shown in Figure 4. The figure shows that, at low $\mathrm{pH}$ values, the combination of carboxylic acids and water, do not form any association structures. At high $\mathrm{pH}$ values, the acid is converted to soap and the combination of soap and water gives an isotropic micellar dispersion. At intermediate $\mathrm{pH}$ values, when both soap and acid are present, all three components are dispersed in a lamellar liquid crystal. Hence by neutralizing 41 percent of the free fatty acids mixture, a lamellar liquid crystal is readily formed as postulated by earlier by Elias.

With that humble beginning, vast research has been directed towards this two entity namely skin and liquid crystal. To date (Date of search: October 30, 2015. Search keyword: 'skin' and "liquid crystal"), a quick search online, show 357,000 articles were published involving skin and liquid crystal (http:// apps.webofknowledge.com).

\section{REFERENCES}

1. Plenig, G.; Marples, R.R., J Invest Dermatol., 1970, 54: 13-18

2. A.M. Kligman; A.M. The Epidermis (W. Montgna Ed.) Academic Press, NY. 1964

3. Grice, K.; Sattar, H.; Baker, H. J Invest Dermatol., 1972, 58: 343-346.

4. Levequa, J.L.; Carson, J.C.; de Rigal, J., J Soc Cosmet Chem., 1979, 30: 333-343.

5. Smith, W.P.; Christensen, M.S.; Nacht, S.; Gans E.H. J Invest Dermatol., 1982. 78: 7-11

6. Imokawa, G.; Hattori M., J Invest Dermatol., 1985, 84: 282-284

7. Elias, P.M.; Brown B.E.; Ziboh, V.A., J Invest Dermatol., 1980, 74: 230-233

8. Abraham, W.; Wertz, P.W.; Downing D.T., J. Lipid Res., 1985, 26(6): 761-766

9. Ranasinghe, A.W.; Wertz, P.W.; Downing D.T.; Mackenzie I.C. , J Invest Dermatol 1986, 86: $187-190$

10. Lampe, M. A.; Burlingame, A. L.; Whitney, J.; Williams, M.L.; Brown, B.E.; Roitman, E.; Elias, P.M., J. Lipid Res., 1983, 24(2): 120130.
11. Lampe, M. A.; Williams, M. L.; Elias, P. M. J. Lipid Res., 1983, 24(2): 131-140.

12. Grayson S.; Elias P.M. , J Invest Dermatol, 1982, 78: 128-135

13. Elias, P.M.; Brown, B.E.; Fritch, P.; Goerke, J.; Gray G. M.; White R.J., J Invest Dermatol., 1979, 73: 339-348

14. McBain, J.W.; Laing, M.E.; Titley, A.F.; J Chem Soc., 1919, 115: 1279-1300

15. Luzzati, V.; Mustacchi, H.; Skoulis, A.; Hudson F., Acta Crystallogr., 1960, 13: 660-667.

16. Ekwall P. Advances in Liquid Crsytals (G.H. Brown Ed.) Academic Press, N.Y., 1979.

17. Friberg, S.E., Naturwissenschaften, 1977, 64: 612-618

18. Fontell, K. In Liquid crystal and plastic crystals, (P.A. Winsor and G.W. Gray Eds.), Ellis Horwood, Chichester, 1974

19. Friberg, S.E.; Osborne, D.W., J Disp Sci. Technol., 1985, 6(4): 485-495.

20. Friberg S.E.; Hamdan, S.; Goldsmith L.; Rhein, L., J Disp Sci. Technol. 1988, 9(4): 371-389.

21. Friberg, S.E.; Goldsmith, L.; Hamdan, S.; Rhein, 
L., Colloids Surfaces. 1988, 30: 1-12.

22. Heuss, E., (1892). Monatshefte für praktische
Dermatologie, 1892, 14: 400-409

23. Schade, H.; Marchionini, A., Klinische Wochenschrift, 1928, 7: 12-14 